Check for updates

Cite this: Chem. Sci., 2019, 10, 6508

๑ All publication charges for this article have been paid for by the Royal Society of Chemistry

Received 8th March 2019

Accepted 17th May 2019

DOI: 10.1039/c9sc01174a

rsc.li/chemical-science

\section{Origins of the odd optical observables in plutonium and americium tungstates $\uparrow$}

\author{
Justin N. Cross, ${ }^{a}$ Tsung-Han Lee, ${ }^{b}$ Chang-Jong Kang, (D) ${ }^{b}$ Yong-Xin Yao, ${ }^{c}$ \\ Samantha K. Cary, ${ }^{a}$ Jared T. Stritzinger, ${ }^{a}$ Matthew J. Polinski, ${ }^{d}$ Carla D. McKinley, \\ Thomas E. Albrecht Schmitt (D) ${ }^{* e}$ and Nicola Lanata (D) *f
}

\begin{abstract}
A series of trivalent f-block tungstates, $\mathrm{MW}_{2} \mathrm{O}_{7}(\mathrm{OH})\left(\mathrm{H}_{2} \mathrm{O}\right)(\mathrm{M}=\mathrm{La}, \mathrm{Ce}, \mathrm{Pr}, \mathrm{Nd}$, and $\mathrm{Pu})$ and $\mathrm{AmWO}_{4}(\mathrm{OH})$, have been prepared in crystalline form using hydrothermal methods. Both structure types take the form of 3D networks where $\mathrm{MW}_{2} \mathrm{O}_{7}(\mathrm{OH})\left(\mathrm{H}_{2} \mathrm{O}\right)$ is assembled from infinite chains of distorted tungstate octahedra linked by isolated $\mathrm{MO}_{8}$ bicapped trigonal prisms; whereas $\mathrm{AmWO}_{4}(\mathrm{OH})$ is constructed from edge-sharing $\mathrm{AmO}_{8}$ square antiprisms connected by distorted tungstate trigonal bipyramids. $\mathrm{PuW}_{2} \mathrm{O}_{7}(\mathrm{OH})\left(\mathrm{H}_{2} \mathrm{O}\right)$ crystallizes as red plates; an atypical color for a Pu(III) compound. Optical absorption spectra acquired from single crystals show strong, broadband absorption in the visible region. A similar feature is observed for $\mathrm{CeW}_{2} \mathrm{O}_{7}(\mathrm{OH})\left(\mathrm{H}_{2} \mathrm{O}\right)$, but not for $\mathrm{AmWO}_{4}(\mathrm{OH})$. Here we demonstrate that these significantly different optical properties do not stem directly from the $5 f$ electrons, as in both systems the valence band has mostly $\mathrm{O}-2 \mathrm{p}$ character and the conduction band has mostly $\mathrm{W}-5 \mathrm{~d}$ character. Furthermore, the quasi-particle gap is essentially unaffected by the $5 f$ degrees of freedom. Despite this, our analysis demonstrates that the f-electron covalency effects are quite important and substantially different energetically in $\mathrm{PuW}_{2} \mathrm{O}_{7}(\mathrm{OH})\left(\mathrm{H}_{2} \mathrm{O}\right)$ and $\mathrm{AmWO}_{4}(\mathrm{OH})$, indicating that the optical gap alone cannot be used to infer conclusions concerning the $f$ electron contribution to the chemical bond in these systems.
\end{abstract}

\section{Introduction}

The past two decades have given rise to a renaissance in our understanding of bonding in f-element compounds that has altered the simplistic view of the chemistry of these elements as being solely dictated by ionic radii and coulombic forces. ${ }^{\mathbf{1 , 2}}$ For example, carbon K-edge X-ray absorption spectroscopy measurements on the actinocenes, $\mathrm{Th}\left(\mathrm{C}_{8} \mathrm{H}_{8}\right)_{2}$ and $\mathrm{U}\left(\mathrm{C}_{8} \mathrm{H}_{8}\right)_{2}$, demonstrated that thorocene, which is typically thought to exhibit almost exclusively ionic interactions between the $\mathrm{Th}^{\mathrm{IV}}$

${ }^{a}$ Chemistry Division and the Plutonium Science and Manufacturing Directorate, Los Alamos National Laboratory, PO Box 1663, Los Alamos, New Mexico, 87545 USA

${ }^{b}$ Department of Physics and Astronomy, Rutgers University, Piscataway, New Jersey o8856, USA

${ }^{c}$ Department of Physics and Astronomy and Ames Laboratory, U.S. Department of Energy, Iowa State University, Ames, Iowa 50011, USA

${ }^{d}$ Department of Chemistry and Biochemistry, Bloomsburg University of Pennsylvania, Bloomsburg, Pennsylvania 17815, USA

${ }^{e}$ Department of Chemistry and Biochemistry, Florida State University, 95 Chieftan Way, 310 DLC, Tallahassee, Florida 32306, USA. E-mail: albrecht-schmitt@chem. fsu.edu

${ }^{f}$ Department of Physics and Astronomy, Aarhus University, 8000, Aarhus C, Denmark. E-mail: lanata@phys.au.dk

$\dagger$ Electronic supplementary information (ESI) available. CCDC 1902033-1902039. For ESI and crystallographic data in CIF or other electronic format see DOI: 10.1039/c9sc01174a center and the ligands, actually has larger orbital mixing than occurs in uranocene. ${ }^{3}$ Likewise, the 4 f orbitals of lanthanides are primarily considered as being "core-like" and noninteracting with surrounding ligands, but a recent Ce(Iv) nitrosyl complex, among the most stable Ce(Iv) complexes reported to date, has covalent interactions involving the $4 \mathrm{f}$ orbitals. ${ }^{4}$ Furthermore, the array of research efforts directed toward understanding the general preference of soft-donor ligands for $5 \mathrm{f}$ over $4 \mathrm{f}$ elements has led to a description of a covalent bond with minimal orbital overlap, but little build-up of electron density between atoms in most cases. ${ }^{5-13}$ However, even this is currently undergoing revision in light of the high kinetic energy of electrons in $5 \mathrm{f}$ elements. ${ }^{14}$ We have added to this discourse on the unusual nature of f-block bonding with the characterization of trivalent lanthanide and actinide borates where the actinides structurally deviating from their lanthanide congeners and from each other. ${ }^{15}$ This deviation, especially with $\mathrm{Cf}^{\mathrm{III}}$, appears to be derived from bonding differences that are characteristic of the individual actinide elements and does not seem to correspond to a monotonic extrapolation from pre-berkelium actinide elements. ${ }^{\mathbf{1 6}}$

In order to uncover the underlying ligand properties that determine whether or not significant differences between $4 \mathrm{f}$ and $5 \mathrm{f}$ elements are expressed, we have also prepared a number of actinide oxoanion compounds that span both the lanthanide 
and actinide series. ${ }^{17-20}$ Currently, some of the most promising oxoanions are those with large hyperpolarizabilities; a quantified value of the susceptibility of a M-O bond to the electric field from impinging light that is calculated from phase-matched second-harmonic generation data. ${ }^{21}$ These oxoanions possess strong second-order Jahn-Teller distortions leading to ligands that possess a wide variety of coordination environments. ${ }^{22-29}$ Specifically, $\mathrm{d}^{0}$ metal oxoanions are attractive ligands to explore bonding differences between the lanthanides and actinides because they have diverse coordination, can polymerize, have high hyperpolarizabilities, and their bonding is fairly well defined. ${ }^{29,30}$ There have been few previously described lowvalent actinides complexed with $\mathrm{d}^{0}$ metal-containing oxoanions despite their potential importance to the nuclear fuel cycle. ${ }^{31-37}$ We have recently reported several plutonium molybdates and a family of chromates that have unusual electronic characteristics and display structural deviation from the lanthanides. . $^{14,38,39}$

Here we explore $\mathrm{d}^{0}$ metal oxoanions with trivalent actinides by synthesizing a series of f-block tungstates of the formula $\mathrm{MW}_{2} \mathrm{O}_{7}(\mathrm{OH})\left(\mathrm{H}_{2} \mathrm{O}\right)(\mathrm{M}=\mathrm{Pu}, \mathrm{La}, \mathrm{Ce}, \mathrm{Pr}, \mathrm{Nd})$ and $\mathrm{AmWO}_{4}(\mathrm{OH})$, where americium structurally diverges under similar reaction conditions. The electronic absorption spectrum of plutonium tungstate features a broad absorption from approximately 300 to $600 \mathrm{~nm}$, giving the crystals an unusual red color. A similar feature is also observed in the spectrum of cerium tungstate. Interestingly, our analysis demonstrates that that the f-electron covalency effects are indeed quite important and substantially different energetically in $\mathrm{PuW}_{2} \mathrm{O}_{7}(\mathrm{OH})\left(\mathrm{H}_{2} \mathrm{O}\right)$ and $\mathrm{AmWO}_{4}(\mathrm{OH})$. On the other hand, we also demonstrate that the unusual color of plutonium tungstate does not stem directly from the $5 \mathrm{f}$ electrons, as in both systems the valence band has mostly O-2p character and the conduction band has mostly $\mathrm{W}-5 \mathrm{~d}$ character. We also find that a similar pattern is realized in the $4 \mathrm{f}$ and $5 \mathrm{f}$ chromates $\alpha$-CsM $\left(\mathrm{CrO}_{4}\right)_{2}(\mathrm{M}=\mathrm{Sm}, \mathrm{Eu}, \mathrm{Am})$ recently synthesized in ref. 14. The fact that color and f-electron covalency are not directly connected in these systems poses general challenges in relation with the fundamental goal of characterizing and understanding bonding in f-element compounds, which can only be addressed by combining state-of-the art experimental and quantum-simulation techniques.

\section{Experimental}

\section{Caution!}

${ }^{239} \mathrm{Pu}\left(t_{1 / 2}=24065\right.$ year $),{ }^{240} \mathrm{Pu}\left(t_{1 / 2}=6537\right.$ year $)$, and ${ }^{243} \mathrm{Am}\left(t_{1 / 2}\right.$ $=7380$ year) represent potential health risks owing to their $\alpha$ and $\gamma$ emission. All studies with plutonium and americium were conducted in a Category II Nuclear Hazard Facility. All experiments were carried out with approved safety operating procedures.

\section{Syntheses}

$\mathrm{WO}_{3}$ (Alfa Aesar 99.8\%), $\mathrm{LaCl}_{3}-7 \mathrm{H}_{2} \mathrm{O}$ (99.9\%, Alfa Aesar), $\mathrm{CeCl}_{3}$ (99.9\%, Alfa Aesar), $\mathrm{PrCl}_{3} \cdot x \mathrm{H}_{2} \mathrm{O}$ (99.9\%, Alfa Aesar), $\mathrm{NdCl}_{3}-$ $\cdot x \mathrm{H}_{2} \mathrm{O}(99.9 \%$, Alfa Aesar), and hydrobromic acid (ACS reagent
48\% Sigma Aldrich) were used as obtained. Plutonium (94\% ${ }^{239} \mathrm{Pu}, 6 \%{ }^{240} \mathrm{Pu}$ ) in the form of $\mathrm{PuCl}_{3}$ was received from LANL. As it had oxidized to the red $\mathrm{PuOCl}_{2}$, reduction back to $\mathrm{Pu}^{3+}$ was accomplished by adding $50 \mu \mathrm{L}$ of conc. $\mathrm{HBr}$, and reducing to a residue in a furnace at $130{ }^{\circ} \mathrm{C}$. The purple residue was then used as the starting Pu source. Reactions were run in Parr 4749 autoclaves with a $10 \mathrm{~mL}$ internal volume PTFE liner for Pu and $\mathrm{Am}$, and $23 \mathrm{~mL}$ internal volume liners for the lanthanides. Deionized water was used in all reactions.

\section{$\mathrm{PuW}_{2} \mathrm{O}_{7}(\mathrm{OH})\left(\mathrm{H}_{2} \mathrm{O}\right)$}

$\mathrm{PuOCl}_{2}(0.0099 \mathrm{~g}, 0.0303 \mathrm{mmol})$ and conc. $\mathrm{HBr}(50 \mu \mathrm{L})$ were heated in a $10 \mathrm{~mL}$ Teflon liner at $130{ }^{\circ} \mathrm{C}$ until reduced to a solid residue. After cooling to room temperature, the liner was moved to an argon-filled glovebox. $\mathrm{WO}_{3}(0.0071 \mathrm{~g}, 0.0306 \mathrm{mmol})$ and $200 \mu \mathrm{L}$ of argon-sparged DI $\mathrm{H}_{2} \mathrm{O}$ were added to the liner. The liner was sealed in a steel jacket and heated to $200{ }^{\circ} \mathrm{C}$ in a box furnace in the glovebox for three days then slowly cooled over two days. The resulting product was rinsed with DI water, and dark-red plates were isolated along with unreacted $\mathrm{WO}_{3}$. Repeating this reaction at $230{ }^{\circ} \mathrm{C}$ produced the same product, but with an increased yield and less unreacted $\mathrm{WO}_{3}$.

\section{$\mathrm{AmWO}_{4}(\mathrm{OH})$}

A residue of $\mathrm{AmCl}_{3} \cdot \mathrm{nH}_{2} \mathrm{O}$ was prepared from $\mathrm{AmO}_{2}$ and $5 \mathrm{M}$ $\mathrm{HCl}$ to produce an approximately $0.010 \mathrm{~g}(0.0286 \mathrm{mmol})$ residue. The residue was dissolved in $200 \mu \mathrm{L}$ of Millipore $\mathrm{H}_{2} \mathrm{O}$ and transferred to a $10 \mathrm{~mL}$ Teflon liner. $\mathrm{WO}_{3}(0.0070 \mathrm{~g}, 302$ $\mathrm{mmol}$ ) was added to the liner which was subsequently sealed in steel jacket and heated to $200{ }^{\circ} \mathrm{C}$ in a box furnace then slowly cooled over two days. It was found that after this treatment, the water had leaked out of the liner leaving an amorphous orange powder and unreacted $\mathrm{WO}_{3}$. $\mathrm{DI}_{2} \mathrm{O}(200 \mu \mathrm{L})$ was added to the received material, the liner sealed in a steel jacket, and reheated in a box furnace to $230{ }^{\circ} \mathrm{C}$ for one day then slowly cooled over two days. After this treatment light-orange crystals of poor quality and no particular shape were isolated. Despite the illdefined shape of the crystals, they still diffract remarkably well.

\section{$\mathrm{LaW}_{2} \mathrm{O}_{7}(\mathrm{OH})\left(\mathrm{H}_{2} \mathrm{O}\right)$}

$\mathrm{LaCl}_{3} \cdot 7 \mathrm{H}_{2} \mathrm{O}(0.0743 \mathrm{~g}, 0.200 \mathrm{mmol}), \mathrm{WO}_{3}(0.0464 \mathrm{~g}, 0.200$ $\mathrm{mmol}$ ), and $2 \mathrm{~mL}$ of $\mathrm{DI}_{2} \mathrm{O}$ were added to a $23 \mathrm{~mL}$ Teflon liner. The liner was sealed in a steel autoclave and heated to $200{ }^{\circ} \mathrm{C}$ for three days then slowly cooled over two days. Colorless plates and unreacted $\mathrm{WO}_{3}$ were isolated.

\section{$\mathrm{CeW}_{2} \mathrm{O}_{7}(\mathrm{OH})\left(\mathrm{H}_{2} \mathrm{O}\right)$}

$\mathrm{CeCl}_{3}(0.0493 \mathrm{~g}, 0.200 \mathrm{mmol}), \mathrm{WO}_{3}(0.0464 \mathrm{~g}, 0.200 \mathrm{mmol})$, and $2 \mathrm{~mL}$ of DI $\mathrm{H}_{2} \mathrm{O}$ were added to a $23 \mathrm{~mL}$ Teflon liner. The liner was sealed in a steel autoclave and heated to $200{ }^{\circ} \mathrm{C}$ for three days then slowly cooled over two days. Yellow plates and unreacted $\mathrm{WO}_{3}$ were isolated. Repeating the reaction at $230{ }^{\circ} \mathrm{C}$ for one day then slowly cooling over two days produced larger crystals of the complex. 


\section{$\operatorname{PrW}_{2} \mathrm{O}_{7}(\mathrm{OH})\left(\mathrm{H}_{2} \mathrm{O}\right)$}

$\mathrm{PrCl}_{3} \cdot 7 \mathrm{H}_{2} \mathrm{O}(0.0710 \mathrm{~g}, 0.200 \mathrm{mmol}), \mathrm{WO}_{3}(0.0464 \mathrm{~g}, 0.200$ $\mathrm{mmol}$ ), and $2 \mathrm{~mL}$ of $\mathrm{DI}_{2} \mathrm{O}$ were added to a $23 \mathrm{~mL}$ Teflon liner. The liner was sealed in a steel autoclave and heated to $200{ }^{\circ} \mathrm{C}$ for three days then slowly cooled over two days. Light-green plates and unreacted $\mathrm{WO}_{3}$ were isolated. Repeating the reaction at $230{ }^{\circ} \mathrm{C}$ for one day then slowly cooling over two days produced larger crystals of the complex.

\section{$\mathrm{NdW}_{2} \mathrm{O}_{7}(\mathrm{OH})\left(\mathrm{H}_{2} \mathrm{O}\right)$}

$\mathrm{NdCl}_{3} \cdot \mathrm{xH}_{2} \mathrm{O}(0.0717 \mathrm{~g}, 0.200 \mathrm{mmol}), \mathrm{WO}_{3}(0.0464 \mathrm{~g}, 0.200$ $\mathrm{mmol}$ ), and $2 \mathrm{~mL}$ of DI $\mathrm{H}_{2} \mathrm{O}$ were added to a $23 \mathrm{~mL}$ Teflon liner. The liner was sealed in a steel autoclave and heated to $200{ }^{\circ} \mathrm{C}$ for three days then slowly cooled over two days. Light-pink plates and unreacted $\mathrm{WO}_{3}$ were isolated. Repeating the reaction at $230{ }^{\circ} \mathrm{C}$ for one day then slowly cooling over two days produced larger crystals of the complex.

\section{Crystallographic studies}

Single crystals of all products were placed on MiTeGen ${ }^{\circledR}$ mounts using viscous Immersion oil and optically aligned on a Bruker D8 Quest X-ray diffractometer using a digital camera. Initial intensity measurements were performed using a I $\mu \mathrm{S} X$ ray source (Mo $\mathrm{K} \alpha, \lambda=0.71073 \AA$ ) with high-brilliance and high-performance focusing multilayer optics. Standard Quest software was used for determination of the unit cells and data collection control. The intensities of reflections of a sphere were collected by a combination of multiple sets of exposures (frames). Each set had a different $\varphi$ angle for the crystal and each exposure covered a range of $0.5^{\circ}$ in $\omega$. A total of 1464 images with an exposure time of 10 to 20 seconds were collected depending on the crystal. The Quest software was used for data integration including Lorentz and polarization corrections. Crystallographic data for all six compounds can be found in Table 1. Crystals of $\mathrm{PuW}_{2} \mathrm{O}_{7}(\mathrm{OH})\left(\mathrm{H}_{2} \mathrm{O}\right)$ were non-merohedrally twinned with a rotation angle of $180^{\circ}$. The program
CELL_NOW was used to index the twinned crystal. Multi-scan absorption corrections were applied using the program SADABS or TWINABS.

\section{UV-vis-NIR spectroscopy}

UV-vis-NIR data were acquired from single or twinned crystals of $\mathrm{PuW}_{2} \mathrm{O}_{7}(\mathrm{OH})\left(\mathrm{H}_{2} \mathrm{O}\right), \mathrm{CeW}_{2} \mathrm{O}_{7}(\mathrm{OH})\left(\mathrm{H}_{2} \mathrm{O}\right), \mathrm{NdW}_{2} \mathrm{O}_{7}(\mathrm{OH})\left(\mathrm{H}_{2} \mathrm{O}\right)$, and $\mathrm{AmWO}_{4}(\mathrm{OH})$ using a Craic Technologies microspectrophotometer. Crystals were placed on quartz slides under immersion oil, and the data was collected from 200 to $1200 \mathrm{~nm}$ for each compound. Data shown are regions of interest.

\section{Results and discussion}

\section{Structure and topological description}

$\mathrm{MW}_{2} \mathrm{O}_{7}(\mathrm{OH})\left(\mathrm{H}_{2} \mathrm{O}\right)(\mathrm{M}=\mathrm{Pu}, \mathrm{La}, \mathrm{Ce}, \mathrm{Pr}$, and $\mathrm{Nd})$ crystallizes in the space group $P 2_{1} / m$ and is a dense 3D network composed of infinite chains of edge-sharing $\mathrm{WO}_{6}$ distorted octahedra, linked by $\mathrm{MO}_{8}$ polyhedra. The corrugated tungstate chains propagate parallel to the $b$ axis. The f-element metal centers are approximated by bicapped trigonal prisms where seven of the eight $\mathrm{O}$ atoms are donated from tungstate, and the remaining $\mathrm{O}$ atom is a coordinating water molecule. ${ }^{40}$ The $\mathrm{MO}_{8}$ units are isolated from each other, but link three tungstate chains, building the network as shown in Fig. 1.

Only one crystallographically unique $\mathbf{M}$ atom and one crystallographically unique $\mathrm{W}$ atom are found in the asymmetric unit. The distorted octahedra of tungstate have two short $(\sim 1.75$ $\AA)$, one intermediate $(\sim 1.88 \AA)$, two normal $(\sim 2.0 \AA)$, and one slightly long $(\sim 2.20 \AA) \mathrm{W}-\mathrm{O}$ bonds. This unit can be thought of in terms of a second-order Jahn-Teller distortion as having a $\mathrm{C}_{2}$ distortion or, in molecular terms, as the cis-tungstyl unit. This elongated $\mathrm{W}-\mathrm{O}$ bond is protonated as indicated by bond valence sum (BVS) calculations providing the additional positive charge necessary to balance the formula. ${ }^{41}$ The trigonal prismatic $\mathrm{O}$ atoms are donated from the tungstate groups as shown in Fig. 2. These $\mathrm{M}-\mathrm{O}$ bonds range from $\sim 2.37 \AA$ to $\sim 2.46$

Table 1 Crystallographic information for $\mathrm{MW}_{2} \mathrm{O}_{7}(\mathrm{OH})\left(\mathrm{H}_{2} \mathrm{O}\right)(\mathrm{M}=\mathrm{Pu}, \mathrm{La}, \mathrm{Ce}, \mathrm{Pr}$, and $\mathrm{Nd})$ and $\mathrm{AmWO}_{4}(\mathrm{OH})$

\begin{tabular}{|c|c|c|c|c|c|c|}
\hline Compound & $\mathrm{La}$ & $\mathrm{Ce}$ & $\mathrm{Pr}$ & $\mathrm{Nd}$ & $\mathrm{Pu}$ & Am \\
\hline Formula Mass & 653.61 & 654.81 & 652.61 & 655.61 & 755.76 & 507.91 \\
\hline Color and habit & Colorless, plate & Yellow, plate & Green, plate & Pink, plate & Red, plate & Orange, plate \\
\hline Space group & $P 2_{1} / m$ & $P 2_{1} / m$ & $P 2_{1} / m$ & $P 2_{1} / m$ & $P 2_{1} / m$ & $P 2_{1} / n$ \\
\hline$a(\AA)$ & $5.991(3)$ & $5.943(2)$ & $5.9040(1)$ & $5.9121(5)$ & $5.8680(5)$ & $5.338(1)$ \\
\hline$b(\AA)$ & $8.736(4)$ & $8.712(2)$ & $8.7129(1)$ & $8.7194(7)$ & $8.6979(7)$ & $12.626(3)$ \\
\hline$c(\AA)$ & $7.165(3)$ & $7.118(2)$ & $7.0935(1)$ & $7.1024(6)$ & $7.0601(6)$ & $6.760(2)$ \\
\hline$\beta\left(^{\circ}\right)$ & $106.044(4)$ & $105.854(3)$ & $105.695(1)$ & $105.700(1)$ & $105.388(2)$ & $111.475(6)$ \\
\hline$V\left(\AA^{3}\right)$ & $360.4(3)$ & $354.5(1)$ & $351.291(9)$ & $352.47(5)$ & $347.42(5)$ & $424.0(2)$ \\
\hline$Z$ & 2 & 2 & 2 & 2 & 2 & 4 \\
\hline$T(\mathrm{~K})$ & 296 & 296 & 296 & 296 & 296 & 100 \\
\hline$\lambda(\AA)$ & 0.71073 & 0.71073 & 0.71073 & 0.71073 & 0.71073 & 0.71073 \\
\hline Maximum $2 \theta$ (deg.) & 28.355 & 28.33 & 28.91 & 28.573 & 30.551 & 31.591 \\
\hline$\rho_{\text {calcd }}\left(\mathrm{g} \mathrm{cm}^{-3}\right)$ & 5.996 & 6.124 & 6.170 & 6.180 & 7.205 & 7.940 \\
\hline$\mu(\operatorname{Mo~K} \alpha)\left(\mathrm{cm}^{-1}\right)$ & 376.78 & 386.91 & 395.07 & 398.29 & 424.22 & 449.66 \\
\hline$R(F)$ for $F_{\mathrm{o}}{ }^{2}>2 \mathrm{~s}\left(F_{\mathrm{o}}\right)^{a}$ & 0.0330 & 0.0192 & 0.0103 & 0.0210 & 0.0200 & 0.0232 \\
\hline$R_{\mathrm{w}}\left(F_{\mathrm{o}}^{2}\right)^{b}$ & 0.0814 & 0.0374 & 0.0259 & 0.0464 & 0.0462 & 0.0424 \\
\hline
\end{tabular}

${ }^{a} R(F)=\sum|| F_{\mathrm{o}}|-| F_{\mathrm{c}}|| / \sum\left|F_{\mathrm{o}}\right| \cdot{ }^{b} R_{\mathrm{w}}\left(F_{\mathrm{o}}{ }^{2}\right)=\left[\sum\left[\mathrm{w}\left(F_{\mathrm{o}}{ }^{2}-F_{\mathrm{c}}{ }^{2}{ }^{2}\right] / \sum \mathrm{w} F_{\mathrm{o}}\right]^{1 / 2}\right.$. 
(a)

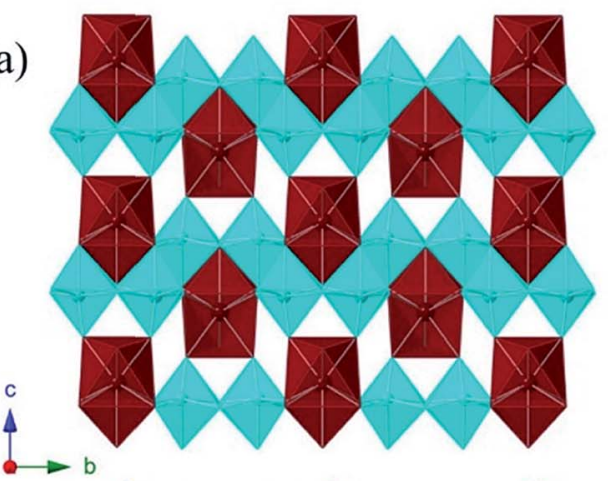

(b)

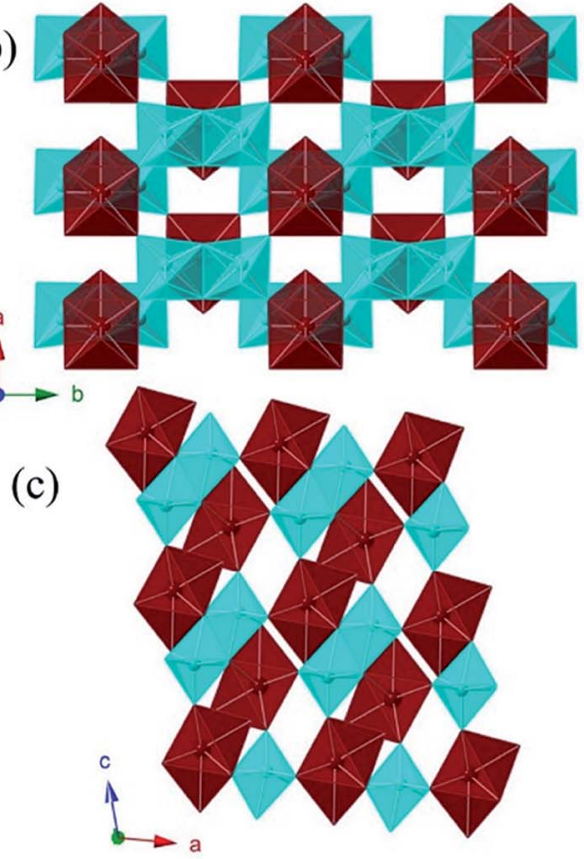

Fig. 1 Polyhedral representations of $\mathrm{PuW}_{2} \mathrm{O}_{7}(\mathrm{OH})\left(\mathrm{H}_{2} \mathrm{O}\right)$ along each axis showing isolated $\mathrm{Pu}(\mathrm{III})$ bicapped trigonal prisms connecting chains of tungstate distorted octahedra. $\mathrm{Pu}^{\text {III }} \mathrm{O}_{8}$ metal centers are within red polyhedra and tungstate metal centers are in blue distorted octahedra.

$\AA$ as can be seen in Table 2 for Pu and Table 3 for the lanthanides. In isotypic structures of $4 \mathrm{f}$ and $5 \mathrm{f}$ compounds, comparisons of bond lengths can provide insight into covalency because the ionic radii match fairly well between certain lanthanides and actinides..$^{17,41-43}$ For $\mathrm{Pu}(\mathrm{III})$ the corresponding lanthanide is $\mathrm{Ce}(\mathrm{III})$; although we have proposed $\mathrm{Nd}$ (III) as being a better match for higher coordination numbers. The average $\mathrm{Pu}-\mathrm{O}$ bond differences are 0.029(5) $\AA$ and 0.018(6) $\AA$ shorter than the $\mathrm{Ce}$ and $\mathrm{Nd}$ bond distances, respectively. Taking into account standard error of the mean, Pu is still statistically shorter than both Ce and Nd. This structure type has not been previously reported as there are few hydrothermally-prepared f-block tungstates that are not polyoxometalate-type complexes.

$\mathrm{AmWO}_{4}(\mathrm{OH})$ crystallizes in the space group $P 2_{1} / n$ and is also a 3D network consisting of layers of edge-sharing Am polyhedra connected by tungstate square bipyramids. The eight coordinate $\mathrm{Am}$ metal centers are approximated by square antiprisms

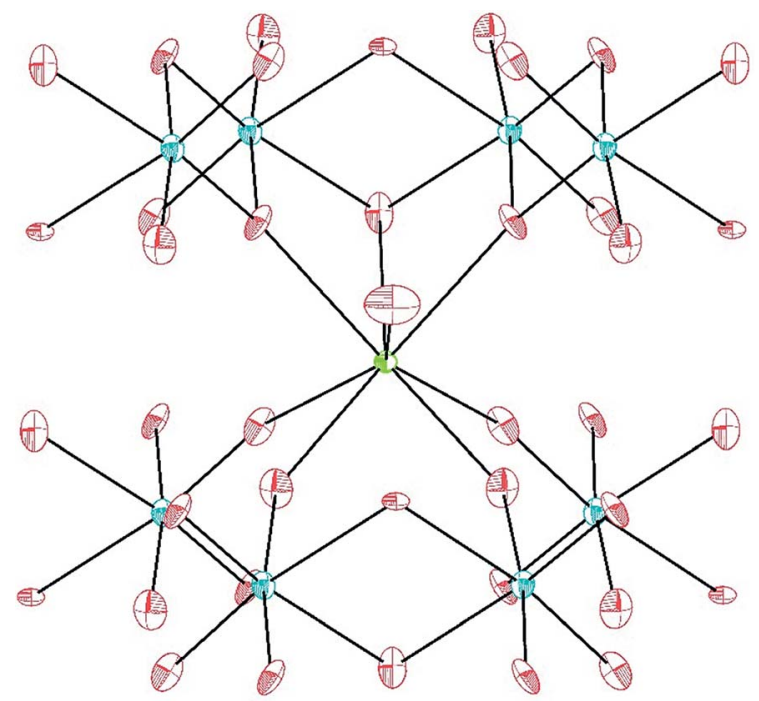

Fig. 2 Ball-and-stick representation of the coordination environment of $\mathrm{Pu}(\mathrm{III})$ in $\mathrm{PuW}_{2} \mathrm{O}_{7}(\mathrm{OH})\left(\mathrm{H}_{2} \mathrm{O}\right)$. The lime-green sphere is $\mathrm{Pu}(\mathrm{III})$, blue spheres are $\mathrm{W}(\mathrm{vI})$, and red spheres are $\mathrm{O}$ atoms. The $\mathrm{O}$ atom at the center of the figure is the coordinating water molecule.

Table 2 Selected bond lengths for $\mathrm{PuW}_{2} \mathrm{O}_{7}(\mathrm{OH})\left(\mathrm{H}_{2} \mathrm{O}\right)$ and $\mathrm{AmWO}_{4}(\mathrm{OH})$

\begin{tabular}{llll}
\hline $\mathrm{PuW}_{2} \mathrm{O}_{7}(\mathrm{OH})\left(\mathrm{H}_{2} \mathrm{O}\right)$ & & $\mathrm{AmWO}_{4}(\mathrm{OH})$ & \\
\hline $\mathrm{Pu}(1)-\mathrm{O}(2)$ & $2.374(4)$ & $\mathrm{Am}(1)-\mathrm{O}(1)$ & $2.357(5)$ \\
$\mathrm{Pu}(1)-\mathrm{O}(2)$ & $2.374(4)$ & $\mathrm{Am}(1)-\mathrm{O}(5)$ & $2.396(5)$ \\
$\mathrm{Pu}(1)-\mathrm{O}(3)$ & $2.396(5)$ & $\mathrm{Am}(1)-\mathrm{O}(2)$ & $2.420(5)$ \\
$\mathrm{Pu}(1)-\mathrm{O}(3)$ & $2.396(5)$ & $\mathrm{Am}(1)-\mathrm{O}(3)$ & $2.449(5)$ \\
$\mathrm{Pu}(1)-\mathrm{O}(4)$ & $2.428(5)$ & $\mathrm{Am}(1)-\mathrm{O}(4)$ & $2.460(5)$ \\
$\mathrm{Pu}(1)-\mathrm{O}(4)$ & $2.428(5)$ & $\mathrm{Am}(1)-\mathrm{O}(4)$ & $2.473(5)$ \\
$\mathrm{Pu}(1)-\mathrm{O}(5)$ & $2.535(8)$ & $\mathrm{Am}(1)-\mathrm{O}(5)$ & $2.496(5)$ \\
$\mathrm{Pu}(1)-\mathrm{O}(1)$ & $2.747(7)$ & $\mathrm{Am}(1)-\mathrm{O}(2)$ & $2.503(5)$ \\
$\mathrm{W}(1)-\mathrm{O}(4)$ & $1.756(5)$ & $\mathrm{W}(1)-\mathrm{O}(1)$ & $1.763(5)$ \\
$\mathrm{W}(1)-\mathrm{O}(3)$ & $1.768(5)$ & $\mathrm{W}(1)-\mathrm{O}(3)$ & $1.764(5)$ \\
$\mathrm{W}(1)-\mathrm{O}(2)$ & $1.884(5)$ & $\mathrm{W}(1)-\mathrm{O}(4)$ & $1.813(5)$ \\
$\mathrm{W}(1)-\mathrm{O}(1)$ & $1.962(3)$ & $\mathrm{W}(1)-\mathrm{O}(2)$ & $1.818(5)$ \\
$\mathrm{W}(1)-\mathrm{O}(2)$ & $2.157(5)$ & $\mathrm{W}(1)-\mathrm{O}(5)$ & $2.398(5)$ \\
$\mathrm{W}(1)-\mathrm{O}(6)$ & $2.199(4)$ & & \\
& & &
\end{tabular}

that edge share with three other Am polyhedra forming layers that propagate parallel to the $[a c]$ plane. These layers are linked by the distorted $\mathrm{WO}_{4} \mathrm{OH}^{3-}$ anions that donate all $\mathrm{O}$ atoms to $\mathrm{Am}$ as shown in Fig. 3. The tungstate geometry can be considered a $4+1$ coordination where the environment goes from tetrahedral with four short bonds (ranging from $\sim 1.76 \AA$ to $1.81 \AA$ ) to distorted trigonal bipyramid with the addition of the long bond (2.398(5) $\AA$ ) to the $\mathrm{OH}^{-}$group. The Am-O bonds range from $2.357(5) \AA$ to $2.503(5) \AA$. This structure type has been previously reported for $\mathrm{Nd}$, however synthetic details are lacking. ${ }^{44}$

\section{UV-vis-NIR spectroscopy}

Absorption data were collected for $\mathrm{MW}_{2} \mathrm{O}_{7}(\mathrm{OH})\left(\mathrm{H}_{2} \mathrm{O}\right)(\mathrm{M}=\mathrm{Pu}$, $\mathrm{Nd}$, and $\mathrm{Ce}$ ) and $\mathrm{AmWO}_{4}(\mathrm{OH})$ on single crystals using a microspectrophotometer and are shown in Fig. 4 . The $\mathrm{Ce}$ and $\mathrm{Pu}$ 
Table 3 Selected bond lengths for $\mathrm{MW}_{2} \mathrm{O}_{7}(\mathrm{OH})\left(\mathrm{H}_{2} \mathrm{O}\right)(\mathrm{M}=\mathrm{La}, \mathrm{Ce}, \mathrm{Pr}$, and $\mathrm{Nd})$

\begin{tabular}{|c|c|c|c|c|c|c|c|}
\hline \multicolumn{2}{|c|}{$\mathrm{LaW}_{2} \mathrm{O}_{7}(\mathrm{OH})\left(\mathrm{H}_{2} \mathrm{O}\right)$} & \multicolumn{2}{|c|}{$\mathrm{CeW}_{2} \mathrm{O}_{7}(\mathrm{OH})\left(\mathrm{H}_{2} \mathrm{O}\right)$} & \multicolumn{2}{|c|}{$\mathrm{PrW}_{2} \mathrm{O}_{7}(\mathrm{OH})\left(\mathrm{H}_{2} \mathrm{O}\right)$} & \multicolumn{2}{|c|}{$\mathrm{NdW}_{2} \mathrm{O}_{7}(\mathrm{OH})\left(\mathrm{H}_{2} \mathrm{O}\right)$} \\
\hline $\mathrm{La}(1)-\mathrm{O}(5)$ & $2.437(9)$ & $\mathrm{Ce}(1)-\mathrm{O}(5)$ & $2.397(4)$ & $\operatorname{Pr}(1)-\mathrm{O}(5)$ & $2.384(2)$ & $\mathrm{Nd}(2)-\mathrm{O}(5)$ & $2.381(5)$ \\
\hline $\mathrm{La}(1)-\mathrm{O}(5)$ & $2.437(9)$ & $\mathrm{Ce}(1)-\mathrm{O}(5)$ & $2.397(4)$ & $\operatorname{Pr}(1)-\mathrm{O}(5)$ & $2.384(2)$ & $\mathrm{Nd}(2)-\mathrm{O}(5)$ & $2.381(5)$ \\
\hline $\mathrm{La}(1)-\mathrm{O}(3)$ & $2.457(9)$ & $\mathrm{Ce}(1)-\mathrm{O}(3)$ & $2.429(4)$ & $\operatorname{Pr}(1)-\mathrm{O}(3)$ & $2.413(2)$ & $\mathrm{Nd}(2)-\mathrm{O}(3)$ & $2.418(6)$ \\
\hline $\mathrm{La}(1)-\mathrm{O}(4)$ & $2.497(9)$ & $\mathrm{Ce}(1)-\mathrm{O}(4)$ & $2.477(4)$ & $\operatorname{Pr}(1)-\mathrm{O}(4)$ & $2.464(2)$ & $\mathrm{Nd}(2)-\mathrm{O}(6)$ & $2.462(5)$ \\
\hline $\mathrm{La}(1)-\mathrm{O}(4)$ & $2.497(9)$ & $\mathrm{Ce}(1)-\mathrm{O}(4)$ & $2.477(4)$ & $\operatorname{Pr}(1)-\mathrm{O}(4)$ & $2.464(2)$ & $\mathrm{Nd}(2)-\mathrm{O}(6)$ & $2.462(5)$ \\
\hline $\mathrm{W}(1)-\mathrm{O}(3)$ & $1.756(9)$ & $\mathrm{W}(1)-\mathrm{O}(4)$ & $1.755(4)$ & $\mathrm{W}(1)-\mathrm{O}(4)$ & $1.754(2)$ & $\mathrm{W}(1)-\mathrm{O}(6)$ & $1.756(5)$ \\
\hline $\mathrm{W}(1)-\mathrm{O}(4)$ & $1.770(8)$ & $\mathrm{W}(1)-\mathrm{O}(3)$ & $1.760(4)$ & $\mathrm{W}(1)-\mathrm{O}(3)$ & $1.759(2)$ & $\mathrm{W}(1)-\mathrm{O}(3)$ & $1.762(5)$ \\
\hline $\mathrm{W}(1)-\mathrm{O}(5)$ & $1.885(9)$ & $\mathrm{W}(1)-\mathrm{O}(5)$ & $1.888(4)$ & $\mathrm{W}(1)-\mathrm{O}(5)$ & $1.884(2)$ & $\mathrm{W}(1)-\mathrm{O}(5)$ & $1.888(5)$ \\
\hline $\mathrm{W}(1)-\mathrm{O}(2)$ & $1.965(7)$ & $\mathrm{W}(1)-\mathrm{O}(2)$ & $1.961(3)$ & $\mathrm{W}(1)-\mathrm{O}(2)$ & $1.963(2)$ & $\mathrm{W}(1)-\mathrm{O}(2)$ & $1.968(4)$ \\
\hline $\mathrm{W}(1)-\mathrm{O}(5)$ & $2.149(9)$ & $\mathrm{W}(1)-\mathrm{O}(5)$ & $2.159(4)$ & $\mathrm{W}(1)-\mathrm{O}(5)$ & $2.163(2)$ & $\mathrm{W}(1)-\mathrm{O}(5)$ & $2.169(6)$ \\
\hline $\mathrm{W}(1)-\mathrm{O}(6)$ & $2.218(9)$ & $\mathrm{W}(1)-\mathrm{O}(6)$ & $2.208(4)$ & $\mathrm{W}(1)-\mathrm{O}(6)$ & $2.202(2)$ & $\mathrm{W}(1)-\mathrm{O}(4)$ & $2.207(5)$ \\
\hline
\end{tabular}

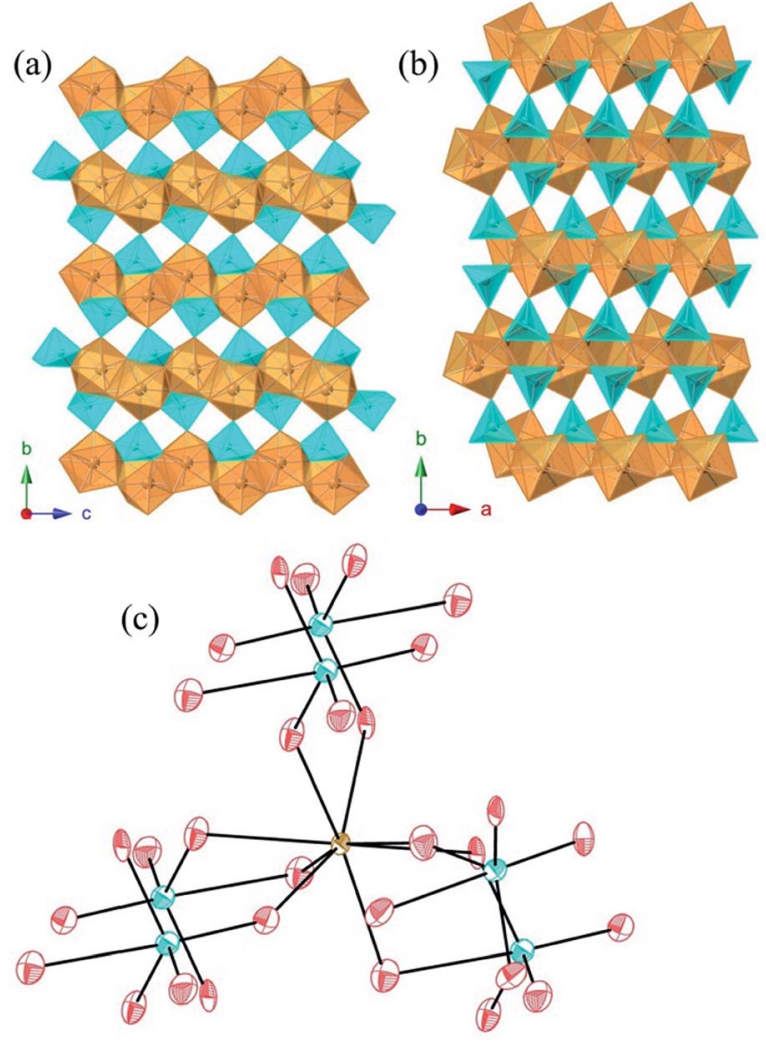

Fig. 3 Polyhedral representation of $\mathrm{AmWO}_{4}(\mathrm{OH})$ where $\mathrm{Am}(\mathrm{III})$ is represented in orange, $\mathrm{W}(\mathrm{VI})$ is represented in blue, and $\mathrm{O}$ atoms as red spheres. ( $a$ and $b$ ) Polyhedral representation along the $a$ and $c$ axes, respectively, displaying the edge sharing chains of $A m(I I) \mathrm{O}_{8}$. (c) Balland-stick coordination of $\mathrm{Am}(\mathrm{III})$ showing all eight $\mathrm{O}$ atoms being donated from tungstate forming an approximate square antiprism.

compounds both exhibit intense broadband features that extend into the UV. The band in the Ce complex leads to the observed yellow color. While yellow Ce(III) complexes are known, it is more typical for Ce(III) oxoanion complexes to be colorless. ${ }^{15,17,18,20,45,46}$ The broad absorption of the Pu complex proceeds into what appears to be the ${ }^{4} \mathrm{~L}_{13 / 2}$ and ${ }^{4} \mathrm{M}_{15 / 2}$ peaks
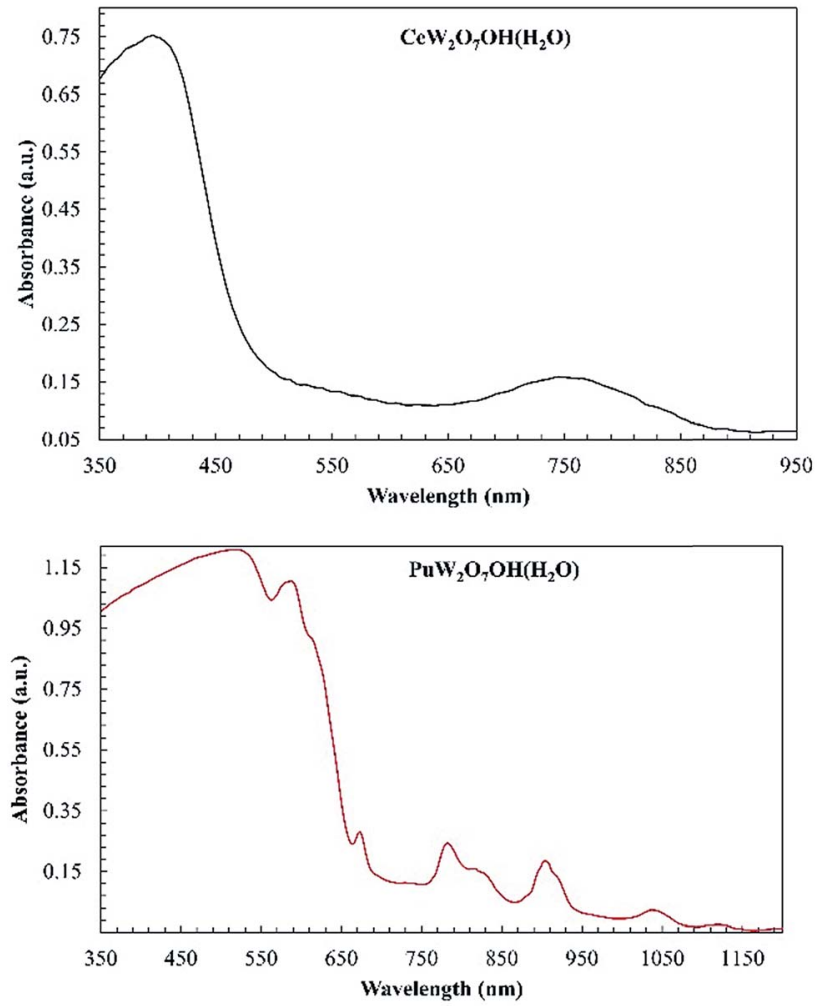

Fig. 4 Electronic absorption spectra of $\mathrm{CeW}_{2} \mathrm{O}_{7}(\mathrm{OH})\left(\mathrm{H}_{2} \mathrm{O}\right.$ ) (top) and $\mathrm{PuW}_{2} \mathrm{O}_{7}(\mathrm{OH})\left(\mathrm{H}_{2} \mathrm{O}\right)$ (bottom). The typical $f-f$ transitions of $\mathrm{Pu}(\mathrm{III})$ are observed starting around $600 \mathrm{~nm}$ and continuing into the lower energies.

around $600 \mathrm{~nm}$ and the ${ }^{6} \mathrm{~F}_{3 / 2}$ peak $\sim 660 \mathrm{~nm}$. The transitions at higher wavelengths are the typical ones observed for $\mathrm{Pu}(\mathrm{III}){ }^{46-49}$ The broadbands and these transitions are responsible for the deep-red color of the crystals that is atypical for $\mathrm{Pu}(\mathrm{III})$ complexes.

The intense broadband is distinctly absent in the $\mathrm{AmWO}_{4}(-$ $\mathrm{OH})$ and $\mathrm{NdW}_{2} \mathrm{O}_{7}(\mathrm{OH})\left(\mathrm{H}_{2} \mathrm{O}\right)$ spectra and the absorption is generally weaker, but the f-f transitions of $\mathrm{Am}$ (III) and $\mathrm{Nd}$ (III) are observed as shown in Fig. 5. The major peak at $510 \mathrm{~nm}$ and the 

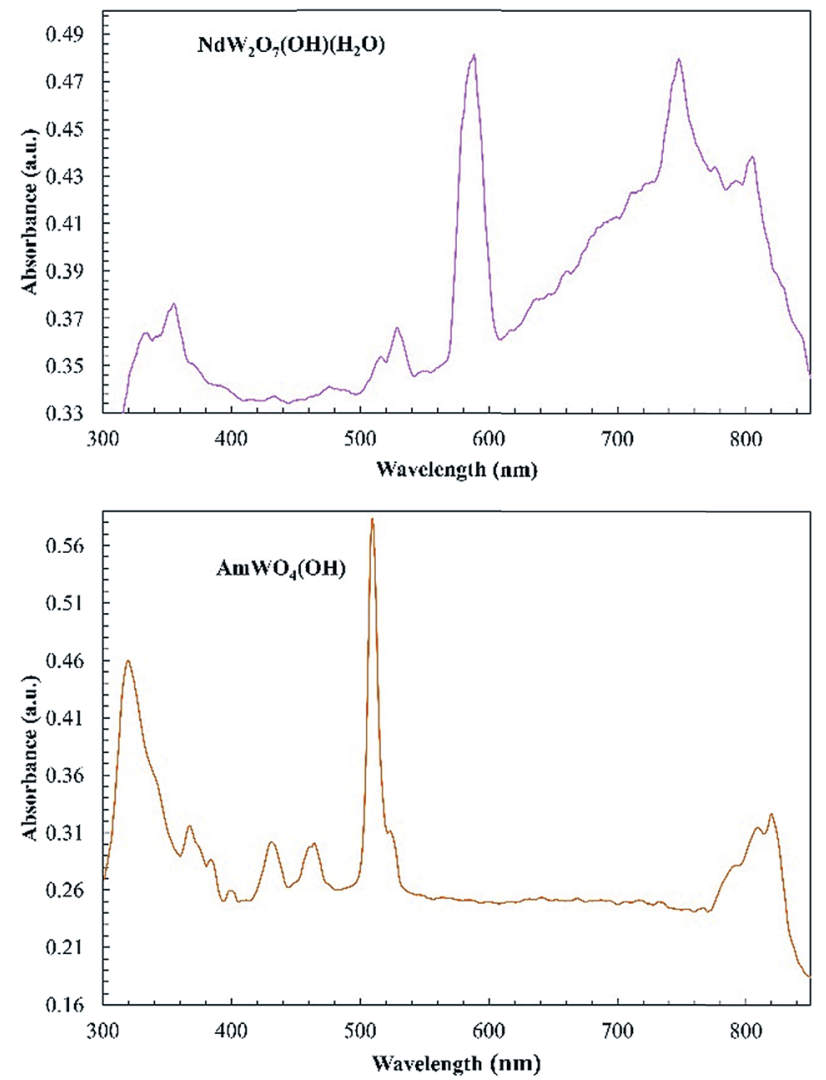

Fig. 5 Electronic absorption spectra of $\mathrm{NdW}_{2} \mathrm{O}_{7}(\mathrm{OH})\left(\mathrm{H}_{2} \mathrm{O}\right)$ (top) and $\mathrm{AmWO}_{4}(\mathrm{OH})$ (bottom). The absorption of these complexes is very weak, but the typical $f-f$ transitions are observed.

small transition at $520 \mathrm{~nm}$ in the Am tungstate can be attributed to the ${ }^{5} \mathrm{~L}_{6}$ and ${ }^{5} \mathrm{D}_{2}$ states. The peaks from 790 to $825 \mathrm{~nm}$ are from the ${ }^{7} \mathrm{~F}_{5}$ and ${ }^{7} \mathrm{~F}_{6}$ transitions.

We have previously noted intense broadband features and unusual color in both $\mathrm{Pu}(\mathrm{III})$ and $\mathrm{Ce}(\mathrm{III})$ compounds coupled with $\mathrm{d}^{0}$ oxoanions. ${ }^{39,50}$ The fact that these are observed at low energies $(\sim 500 \mathrm{~nm})$ only in the Pu and Ce compounds and not in Am or Nd is noteworthy. The excited state of Ce(III) is known to be $5 \mathrm{~d}$ and easily perturbed by ligand-field effects..$^{51-54}$ Given this, there might be significant interactions between the frontier orbitals of the $\mathrm{d}^{0}$ metal anion and the $5 \mathrm{~d}$ orbital on $\mathrm{Ce}(\mathrm{III})$ leading to the broad absorption observed. This was the case with the recently published Ce polyoxometallate, where the DFT calculations showed that charge transfer occurred between $\mathrm{Ce}(\mathrm{III})$ and $\mathrm{W}(\mathrm{VI})$ resulting in its photocatalytic properties. ${ }^{54} \mathrm{Am}$ (III) and $\mathrm{Nd}$ (III) tungstate do not have the low energy CT band. The CT is shifted to higher energies that cannot be fully resolved with the microspectrophotometer. A possible explanation is that these features are related to the ease in accessing the M(IV) oxidation state. Both Ce(III) and $\mathrm{Pu}(\mathrm{III})$ are able to access tetravalent states fairly easily arise from redox instability of $\mathrm{Ce}(\mathrm{III})$ and $\mathrm{Pu}(\mathrm{III})$ where the absorptions seen are metal-to-ligand CT transitions. The features seen here are very similar to the features seen in the electronic spectra of transition metal tungstates. ${ }^{55}$ These spectra indicate a metal-to-metal charge transfer (MMCT) where the partially occupied An/Ln metal orbitals transfer to the empty tungsten $5 \mathrm{~d}$ orbitals. ${ }^{55}$ Identifying exactly which orbitals are involved and how the orbital energies change going from $4 \mathrm{f}$ to $5 \mathrm{f}$ requires theoretical studies, which we discuss in the next section. ${ }^{56}$

\section{Band structures of $\mathrm{PuW}_{2} \mathrm{O}_{7}(\mathrm{OH})\left(\mathrm{H}_{2} \mathrm{O}\right)$ and $\mathrm{AmWO}_{4}(\mathrm{OH})$}

Rather than continuing to speculate on the origins of the unusual colors exhibited in these systems-and their possible connection with 5 f-electron covalency,--here we calculate the electronic structure of $\mathrm{PuW}_{2} \mathrm{O}_{7}$ and $\mathrm{AmWO}_{4}$ employing the local density approximation (LDA $)^{57}$ to density functional theory $(\mathrm{DFT})^{58,59}$ in combination with dynamical mean field theory $(\mathrm{LDA}+\mathrm{DMFT})^{60-62}$ and in combination with the Gutzwiller approximation (LDA $+\mathrm{GA}){ }^{63-67}$ which are techniques specifically designed to capture the electron correlations beyond the singleparticle picture underlining classic approximations to DFT. ${ }^{68-70}$

Both GA and DMFT have been interfaced with the DFT code WIEN2 $\mathrm{k}^{71}$ utilizing the implementation described in ref. 72 and employing the standard fully-localized limit form for the double-counting functional. ${ }^{73}$ Consistently with previous work, ${ }^{14}$ in our calculations we assume that the screened values of the Hund's coupling constant and the local Coulomb interaction strength are $J=0.7 \mathrm{eV}$ and $U=6.0 \mathrm{eV}$, respectively. The LDA + DMFT calculations are performed at room temperature $(T$ $=290 \mathrm{~K})$ utilizing the continuous time quantum Monte Carlo (CTQMC) impurity solver, ${ }^{72,74}$ while the LDA + GA calculations are performed at $T=0 \mathrm{~K}$.

The LDA + DMFT angle-resolved photoemission spectra (ARPES), ${ }^{75}$ the corresponding 5 f-electron contribution to the quasi-particle density of states (DOS) and the $j=5 / 2$ and $j=7 / 2$ components of the self-energy of these two materials, where $j$ is the single-particle total angular momentum, are shown in panels (a-c) of Fig. 6 and 7. The bare unpolarized LDA band structures are also reported in panel (d). Our simulations indicate that the quasiparticle gaps of $\mathrm{PuW}_{2} \mathrm{O}_{7}$ and $\mathrm{AmWO}_{4}$ are about $1.2 \mathrm{eV}$ and $2.5 \mathrm{eV}$, respectively, in agreement with our UVvis-NIR absorption experiments. The fact that the LDA + DMFT band structure displays pronounced incoherent features and is considerably different with respect to bare LDA indicates clearly that, as expected, the f-electron correlations influence dramatically the electronic structure of these materials. The different behavior of the $j=5 / 2$ and $j=7 / 2$ components of the self-energy and the resolved DOS indicate that also the SOC effect is very important in both systems.

In order to shed light on the physical origin of the pronounced differences between the optical properties of $\mathrm{PuW}_{2} \mathrm{O}_{7}$ and $\mathrm{AmWO}_{4}$, as well as on the influence of the $\mathrm{f}$ electron correlations on the spectra of these 2 materials, it is very insightful to plot the LDA bands modified by removing artificially the contribution of the f-electron degrees of freedom in the LDA Kohn-Sham Hamiltonian, ${ }^{59}$ i.e., by setting to 0 the hybridization between the $5 \mathrm{f}$ orbitals and their environment, see panels (e) of Fig. 6 and 7. Interestingly, we observe that the so-obtained low-energy band structures are very similar to the 

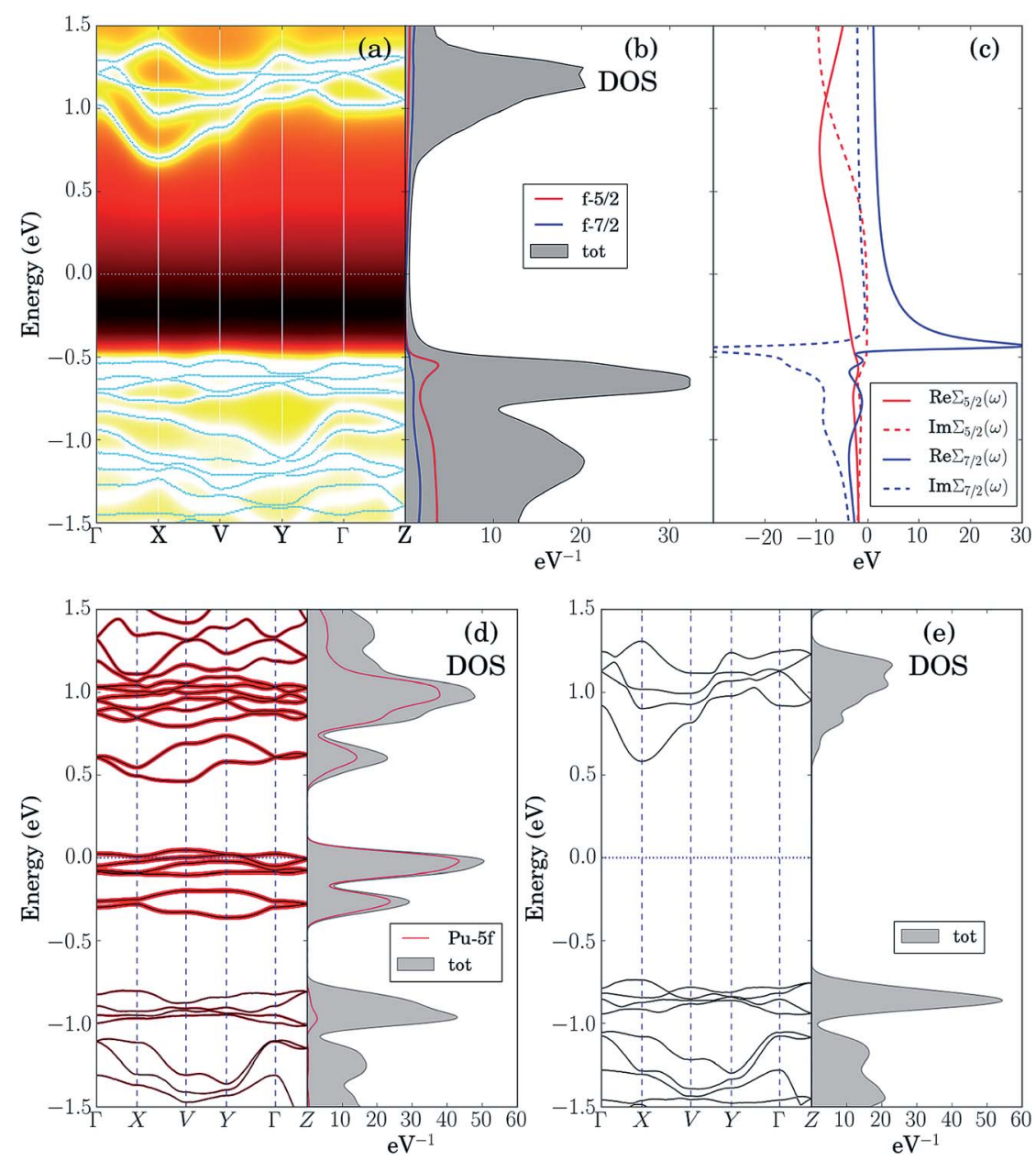

Fig. 6 Theoretical analysis spectral properties of PuW2O7(OH)(H2O): (a) LDA + DMFT ARPES spectra computed at $T=290 \mathrm{~K}$ and corresponding quasi-particle bands. (b) Spectral contributions to the Pu-5f 5/2 and 7/2 contributions to the DOS. (c) 5/2 and 7/2 components of the self-energy. (d) Bare unpolarized LDA bands and corresponding Pu-5f 5/2 and 7/2 contributions to the DOS. (e) Modified LDA bands obtained by setting to 0 the hybridization between the $5 f$ orbitals and their environment.

physical LDA + DMFT quasi-particle bands. Furthermore, in both systems the valence band has mostly $\mathrm{O}-2 \mathrm{p}$ character, while the conduction band has mostly W-5d character. This analysis demonstrates that the pronounced differences between the optical gaps of these 2 compounds do not stem directly from the $5 \mathrm{f}$ degrees of freedom. On the other hand, the pronounced incoherent features of the LDA + DMFT bands and the resolved DOS are an indirect indication of the fact that the O-2p and $5 f$ degrees of freedom are hybridized, which suggests that the Am$\mathrm{O}$ and $\mathrm{Pu}-\mathrm{O}$ chemical bonds are not purely ionic. Here we quantify the importance of the $5 \mathrm{f}$-electron covalency effects in the materials considered utilizing the procedure developed in ref. 14, i.e., we compare the physical LDA + GA ground-state energy of the systems with the energy that the system would have if the $5 \mathrm{f}$ degrees of freedom were entirely disentangled from the rest of the system, i.e., with the total energy minimum realizable in a quantum state with $5 \mathrm{f}$ valence degrees of freedom hosting exactly the nominal value of electrons ( 6 electrons for $\mathrm{Am}$ and 5 electrons for $\mathrm{Pu}$ ), completely decoupled from the rest of the system. According to our calculations, the so-obtained measure of covalency is $\Delta E_{\text {cov }} \approx 0.72 \mathrm{eV} \mathrm{f.u} .^{-1}$ for $\mathrm{PuW}_{2} \mathrm{O}_{7}$ and $\Delta E_{\text {cov }} \approx 1.08 \mathrm{eV}$ f.u. ${ }^{-1}$ for $\mathrm{AmWO}_{4}$.

A complementary indication of covalency is provided by the local $5 f$-electron reduced density matrix, which is formally obtained from the ground-state wavefunction of the systems by tracing out all degrees of freedom except those of the $5 \mathrm{f}$ shell. In Table 4 and Table 5 are shown the quantum labels of the eigenstates of the local $\mathrm{Pu}-5 \mathrm{f}$ and $\mathrm{Am}-5 \mathrm{f}$ electron reduced density matrix of $\mathrm{PuW}_{2} \mathrm{O}_{7}$ and $\mathrm{AmWO}_{4}$ with highest probability weights. Our calculations indicate that both systems are "mixed-valent compounds", as they display non-negligible charge fluctuations. In particular, we note that the sum of the probability weights arising from other multiplets besides the highest ones (which correspond to the nominal atomic groundstate configurations) is about $24 \%$ for $\mathrm{Pu}$ and $13 \%$ for $\mathrm{Am}$.

In summary, our analysis indicates that the f-electron covalency effects have a strong influence on the total energy and the chemical bonds in $\mathrm{PuW}_{2} \mathrm{O}_{7}(\mathrm{OH})\left(\mathrm{H}_{2} \mathrm{O}\right)$ and $\mathrm{AmWO}_{4}(\mathrm{OH})$. Indirect signatures of f-electron covalency can be observed also in the ARPES spectra, which displays pronounced incoherent 

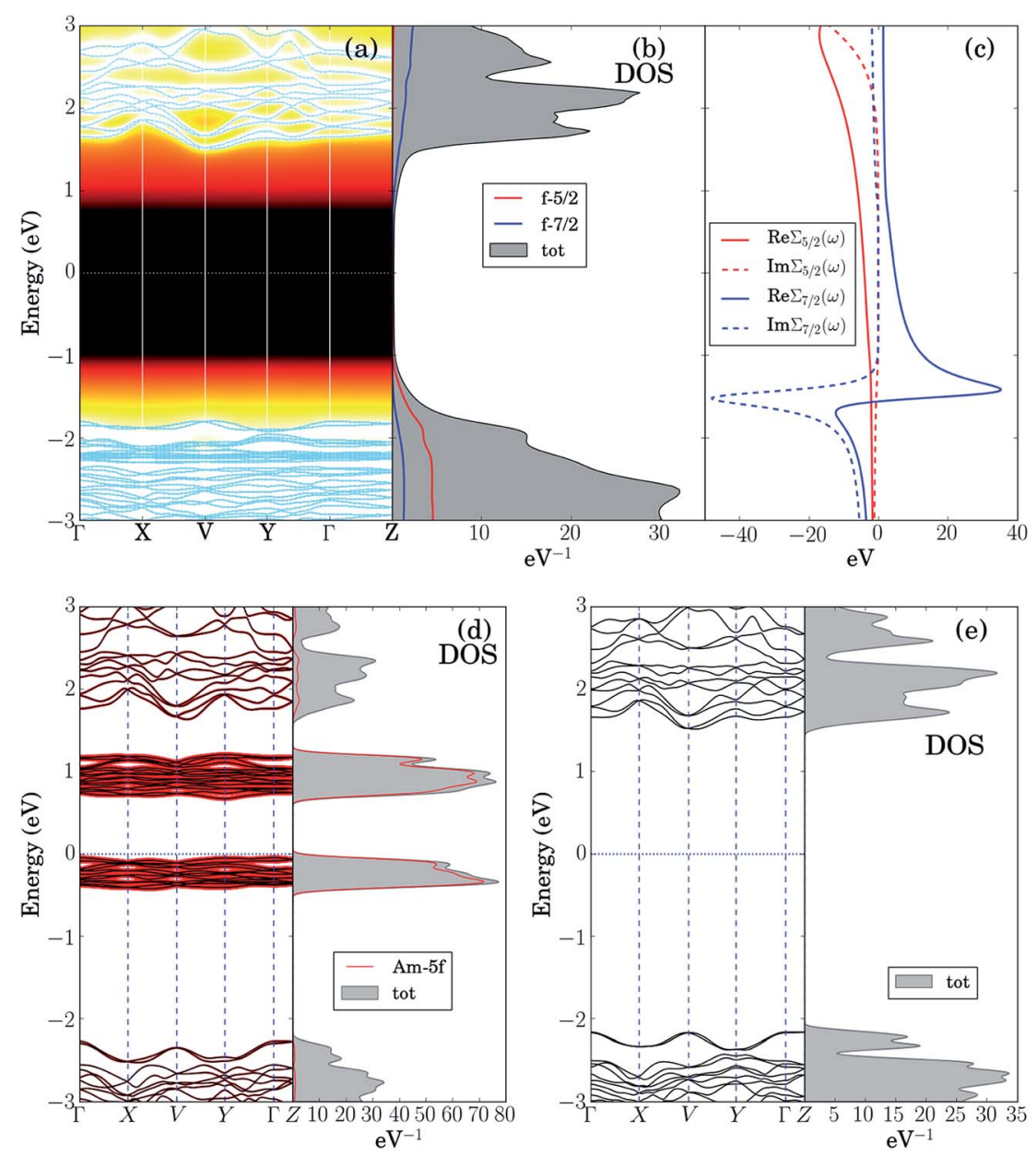

Fig. 7 Theoretical analysis spectral properties of $\mathrm{AmWO}_{4}(\mathrm{OH})$ : (a) LDA + DMFT ARPES spectra computed at $T=290 \mathrm{~K}$ and corresponding quasiparticle bands. (b) Spectral contributions to the Pu- $5 f$ 5/2 and $7 / 2$ contributions to the DOS. (c) $5 / 2$ and $7 / 2$ components of the self-energy. (d) Bare unpolarized LDA bands and corresponding Pu- $5 f$ 5/2 and 7/2 contributions to the DOS. (e) Modified LDA bands obtained by setting to 0 the hybridization between the $5 f$ orbitals and their environment.

Table 4 Parameters of the Pu-5f reduced density matrix of $\mathrm{PuW}_{2} \mathrm{O}_{7}$ computed employing LDA + GA assuming $U=6 \mathrm{eV}$ and $J=0.7 \mathrm{eV}$. Largest probability weights $W_{i}$, corresponding quantum labels $N_{i}$ (number of electrons) and $J_{i}$ (total angular momentum)

\begin{tabular}{lllll}
\hline$i$ & 1 & 2 & 3 & 4 \\
$w_{i}$ & 0.76 & 0.061 & 0.059 & 0.017 \\
$N_{i}$ & 5 & 6 & 4 & 6 \\
$J_{i}$ & 2.5 & 0 & 4 & 6
\end{tabular}

Table 5 Parameters of the Am- $5 f$ reduced density matrix of $\mathrm{AmWO}_{4}$ computed employing LDA + GA assuming $U=6 \mathrm{eV}$ and $\mathrm{J}=0.7 \mathrm{eV}$. Largest probability weights $W_{i}$, corresponding quantum labels $N_{i}$ (number of electrons) and $J_{i}$ (total angular momentum)

\begin{tabular}{lllll}
\hline$i$ & 1 & 2 & 3 & 4 \\
$w_{i}$ & 0.87 & 0.082 & 0.035 & 0.002 \\
$N_{i}$ & 6 & 7 & 5 & 6 \\
$J_{i}$ & 0 & 3.5 & 2.5 & 6
\end{tabular}

features and f-electron hybridization effects at low energies. On the other hand, in both systems the valence bands have mostly $\mathrm{O}-2 \mathrm{p}$ character and the conduction bands have mostly $\mathrm{W}-5 \mathrm{~d}$ character. Furthermore, the quasi-particle gap is essentially unaffected by the $5 \mathrm{f}$ degrees of freedom. Consequently, while the 5f-covalency effects are energetically important, the pronounced differences observed between the optical properties of these compounds do not stem directly from the $5 \mathrm{f}$ degrees of freedom. Interestingly, as shown in the supplemental material in Fig. S5-S7, $\dagger$ a similar situation occurs also in 3 different $4 \mathrm{f}$ and $5 \mathrm{f}$ chromates: $\alpha-\mathrm{CsM}\left(\mathrm{CrO}_{4}\right)_{2}(\mathrm{M}=\mathrm{Sm}, \mathrm{Eu}, \mathrm{Am})$.

\section{Conclusions}

Atypical coloration of compounds has been a harbinger of the need for understanding electronic structure since the earliest days of chemistry. It is one of the driving forces behind the evolution of ligand-field theory from crystal-field theory because the latter does not allow for the correct prediction of the color of most transition metal complexes because it does not account for the role that the $\mathrm{d}$ orbitals play in covalent bonding. ${ }^{76}$ In the 
actinide compounds unusual coloration can indeed be indicative of unusual metal-ligand interactions. ${ }^{38,77,78}$ However, the tendency is to jump to the conclusion that the coloration of compounds and complexes that are different from that observed from the respective hydrated cations (e.g. $\left.\left[\mathrm{An}\left(\mathrm{H}_{2} \mathrm{O}\right)_{9}\right]^{3+}\right)$ can always be ascribed to significant utilization of the metal-based frontier orbitals in bonding. For example, $\left[\mathrm{Pu}\left(\mathrm{H}_{2} \mathrm{O}\right)_{9}\right]^{3+}$ both in concentrated solutions and the solid-state exhibits deep-purple coloration. Yet, both $\mathrm{Pu}^{\mathrm{III}}\left(\mathrm{Se}_{2} \mathrm{PPh}_{2}\right)_{3}(\mathrm{py})_{2}$ and $\left[\mathrm{Pu}^{\mathrm{III}}(\mathrm{dpa})\left(\mathrm{H}_{2} \mathrm{O}\right)_{4}\right] \mathrm{Br}(\mathrm{dpa}=$ dipicolinate $)$ are green. In both of these examples the green color is ascribed to ligand-to-metal charge transfer, and in the latter case it facilitates fascinating oxidation though mixed-valent compounds that can exhibit intervalence charge transfer. ${ }^{79}$ However, what these examples fail to capture is that color arises from many sources and is not always based on the electronic features that are created from single metal centers. In gemstones, coloration is commonly created by trace dopants and defects.

The study of the $5 \mathrm{f}$ tungstates $\mathrm{PuW}_{2} \mathrm{O}_{7}(\mathrm{OH})\left(\mathrm{H}_{2} \mathrm{O}\right)$ and $\mathrm{AmWO}_{4}(\mathrm{OH})$ addressed in this work, supplemented by the analysis of the $4 \mathrm{f}$ and $5 \mathrm{f}$ chromates $\alpha-\mathrm{CsM}\left(\mathrm{CrO}_{4}\right)_{2}(\mathrm{M}=\mathrm{Sm}, \mathrm{Eu}$, $\mathrm{Am})^{14}$ shown in the supplemental material, provides a new variation on this theme, where the f-orbitals are strongly entangled with $\mathrm{O}-2 \mathrm{p}$ electrons, but this hybridization plays no role in the odd colors of the compounds-whose variations are mostly dictated by the different character of the $\mathrm{W}-5 \mathrm{~d}$ bands in the tungstates and in the $\mathrm{Cr}-3 \mathrm{~d}$ bands in the chromates. These insights exemplify how combining state-of-the-art experimental and quantum-simulation techniques is essential for characterizing and understanding chemical bonds (and, in particular, their connection with the optical properties) in f-electron systems.

\section{Conflicts of interest}

The authors declare no competing financial interests.

\section{Acknowledgements}

All experimental studies were supported by the U.S. Department of Energy, Basic Energy Sciences, Heavy Elements Chemistry Program, U.S. Department of Energy, under Grant DE-FG0213ER16414. Theoretical studies were supported by the U.S. Department of Energy as a part of the Center for Actinide Science and Technology (CAST) funded by the Energy Frontiers Research Program, under Award Number DE-SC0016568. N. L. was also supported by the VILLUM FONDEN via the Centre of Excellence for Dirac Materials (Grant No. 11744). T.-H. L and C.J. K were supported by the Department of Energy under Grant No. DE-FG02-99ER45761. Y. Y. was supported by the U.S. Department of energy, Office of Science, Basic Energy Sciences, as a part of the Computational Materials Science Program. This work used the Extreme Science and Engineering Discovery Environment (XSEDE) funded by NSF under Grants No. TGDMR170121.

\section{Notes and references}

1 G. R. Choppin, J. Alloys Compd., 2002, 344, 55-59.

2 N. A. Edelstein, J. Fuger, J. J. Katz and L. R. Morss, in The Chemistry of the Actinides and Transactinide Elements, ed. L. R. Morss, N. A. Edelstein, J. Fuger and J. J. Katz, Springer, Berlin, 4th edn, 2011, vol. 3, pp. 1753-1835.

3 S. G. Minasian, J. M. Keith, E. R. Batista, K. S. Boland, D. L. Clark, S. A. Kozimor, R. L. Martin, D. K. Shuh and T. Tyliszczak, Chem. Sci., 2014, 5, 351-359.

4 J. A. Bogart, A. J. Lewis, S. A. Medling, N. A. Piro, P. J. Carroll, C. H. Booth and E. J. Schelter, Inorg. Chem., 2013, 52, 1160011607.

5 M. L. Neidig, D. L. Clark and R. L. Martin, Coord. Chem. Rev., 2013, 257, 394-406.

6 I. Kirker and N. Kaltsoyannis, Dalton Trans., 2011, 40, 124131.

7 M. J. Tassell and N. Kaltsoyannis, Dalton Trans., 2010, 39, 6719-6725.

8 I. D. Prodan, G. E. Scuseria and R. L. Martin, Phys. Rev. B: Condens. Matter Mater. Phys., 2007, 76, 033101.

9 A. J. Gaunt, S. D. Reilly, A. E. Enriquez, B. L. Scott, J. A. Ibers, P. Sekar, K. I. M. Ingram, N. Kaltsoyannis and M. P. Neu, Inorg. Chem., 2008, 47, 29-41.

10 M. P. Jensen and A. H. Bond, J. Am. Chem. Soc., 2002, 124, 9870-9877.

11 M. Mazzanti, R. L. Wietzke, J. Pecaut, J. M. Latour, P. Maldivi and M. Remy, Inorg. Chem., 2002, 41, 2389-2399.

12 T. Mehdoui, J. C. Berthet, P. Thuéry and M. Ephritikhine, Dalton Trans., 2004, 4, 579-590.

13 A. J. Gaunt, B. L. Scott and M. P. Neu, Angew. Chem., Int. Ed., 2006, 45, 1638-1641.

14 S. S. Galley, A. A. Arico, T.-H. Lee, X. Deng, Y.-X. Yao, J. M. Sperling, V. Proust, J. S. Storbeck, V. Dobrosavljevic, J. N. Neu, T. Siegrist, R. E. Baumbach, T. E. AlbrechtSchmitt, N. Kaltsoyannis and N. Lanatà, J. Am. Chem. Soc., 2018, 140, 1674-1685.

15 M. J. Polinski, D. J. Grant, S. Wang, E. V. Alekseev, J. N. Cross, E. M. Villa, W. Depmeier, L. Gagliardi and T. E. AlbrechtSchmitt, J. Am. Chem. Soc., 2012, 134, 10682-10692.

16 M. J. Polinski, E. B. Garner III, R. Maurice, N. Planas, J. T. Stritzinger, T. G. Parker, J. N. Cross, T. D. Green, E. V. Alekseev, S. M. Van Cleve, W. Depmeier, L. Gagliardi, M. Shatruk, K. L. Knappenberger, G. Liu, S. Skanthakumar, L. Soderholm, D. A. Dixon and T. E. Albrecht-Schmitt, Nat. Chem., 2014, 6, 387-392.

17 J. N. Cross, E. Villa, S. Wang, J. Diwu, M. J. Polinski and T. E. Albrecht-Schmitt, Inorg. Chem., 2012, 51, 8419-8424.

18 J. Diwu, D. J. Grant, S. Wang, L. Gagliardi and T. E. AlbrechtSchmitt, Inorg. Chem., 2012, 51, 6906-6915.

19 J. Lin, J. Diwu, J. N. Cross, E. M. Villa and T. E. AlbrechtSchmitt, Inorg. Chem., 2012, 51, 10083-10085.

20 J. Lin, J. N. Cross, J. Diwu, N. A. Meredith and T. E. AlbrechtSchmitt, Inorg. Chem., 2013, 52, 4277-4281.

21 J. Goodey, J. Broussard and P. S. Halasyamani, Chem. Mater., 2002, 14, 3174-3180. 
22 H. A. Jahn and E. Teller, Proc. R. Soc. London, Ser. A, 1937, 161, 220-235.

23 R. A. Wheeler, M. H. Whangbo, T. Hughbanks, R. Hoffman, J. K. Burdett and T. A. Albright, J. Am. Chem. Soc., 1986, 108, 2222-2236.

24 R. G. Pearson, J. Mol. Struct.: THEOCHEM, 1983, 103, 25-34.

25 S. K. Kang, H. Tang and T. A. Albright, J. Am. Chem. Soc., 1993, 115, 1971-1981.

26 R. E. Cohen, Nature, 1992, 358, 136-138.

27 J. K. Burdett, Molecular Shapes, Wiley-Interscience, New York, 1980.

28 M. Kunz and I. D. Brown, J. Solid State Chem., 1995, 115, 395406.

29 P. S. Halasyamani and K. R. Poeppelmeier, Chem. Mater., 1998, 10, 2753-2769.

30 S. G. Minasian, J. M Keith, E. R. Batista, K. S. Boland, J. A. Bradley, S. R. Daly, S. A. Kozimor, W. W. Lukens, R. L. Martin, D. Nordlund, G. T. Seidler, D. K. Shuh, D. Sokaras, T. Tyliszczak, G. L. Wagner, T. C. Weng and P. Yang, J. Am. Chem. Soc., 2013, 135, 1864-1871.

31 R. A. Penneman, R. G. Haire and M. H. Lloyd, presented in part at ACS Symposium Series, Washington, D.C., 1980.

32 E. C. Buck, D. J. Wronkiewicz, P. A. Finn and J. K. Bates, J. Nucl. Mater., 1997, 249, 70-76.

33 S. V. Krivovichev, P. C. Burns and I. G. Tananaev, in Structural Chemistry of Inorganic Actinides, ed. S. V. Krivovichev, P. C. Burns and I. G. Tananaev, Elsevier, Amsterdam, 1st edn, 2007, ch. 4, pp. 95-182.

34 N. D. Dahale, M. Keskar and K. D. S. Mudher, J. Alloys Compd., 2006, 415, 244-250.

35 A. Tabuteau, M. Pages and W. Freundlich, Mater. Res. Bull., 1972, 7, 691-697.

36 A. Tabuteau and M. Pages, J. Solid State Chem., 1978, 26, 153158.

37 M. N. Sokolova, A. M. Fedosseev, G. B. Andreev, N. A. Budantseva, A. B. Yusov and P. Moisy, Inorg. Chem., 2009, 48, 9185-9190.

38 J. N. Cross, P. M. Duncan, E. M. Villa, M. J. Polinski, J.-M. Babo, E. V. Alekseev, C. H. Booth and T. E. AlbrechtSchmitt, J. Am. Chem. Soc., 2013, 135, 2769-2775.

39 J. N. Cross, S. K. Cary, J. T. Stritzinger, M. J. Polinski and T. E. Albrecht-Schmitt, Inorg. Chem., 2014, 53, 3148-3152.

40 J. Xu, E. Radkov, M. Ziegler and K. N. Raymond, Inorg. Chem., 2000, 39, 4156-4164.

41 N. E. Brese and M. O'Keefe, Acta Crystallogr., Sect. B: Struct. Sci., 1991, 47, 192-197.

42 M. B. Jones, A. J. Gaunt, J. C. Gordon, N. Kaltsoyannis, M. P. Neu and B. L. Scott, Chem. Sci., 2013, 4, 1189-1203.

43 R. D. Shannon, Acta Crystallogr., Sect. A: Cryst. Phys., Diffr., Theor. Gen. Crystallogr., 1976, 32, 751-767.

44 R. F. Klevtsova and S. V. Borisov, Sov. Phys. Cryst., 1970, 14, 776-778.

45 M. J. Polinski, S. Wang, E. V. Alekseev, J. N. Cross, W. Depmeier and T. E. Albrecht-Schmitt, Inorg. Chem., 2012, 51, 11541-11548.
46 M. J. Polinski, S. Wang, J. N. Cross, E. V. Alekseev, W. Depmeier and T. E. Albrecht-Schmitt, Inorg. Chem., 2012, 51, 7859-7866.

47 C. Apostolidis, B. Schimmelpfennig, N. Magnani, P. Lindqvist-Reis, O. Walter, R. Sykora, A. Morgenstern, E. Colineau, R. Caciuffo, R. Klenz, R. G. Haire, J. Rebizant, F. Bruchertseifer and T. Fanghänel, Angew. Chem., Int. Ed., 2010, 49, 6343-6347.

48 W. T. Carnall, P. R. Fields and R. G. Pappalardo, J. Chem. Phys., 1970, 53, 2922-2938.

49 N. L. Banik, B. Schimmelpfennig, C. M. Marquardt, B. Brendebach, A. Geista and M. A. Denecke, Dalton Trans., 2010, 39, 5117-5122.

50 T. M. Eaton, J. Lin, J. N. Cross, J. T. Stritzinger and T. E. Albrecht-Schmitt, Chem. Commun., 2014, 50, 36683670.

51 R. R. Jacobs, W. F. Krupke and M. J. Weber, Appl. Phys. Lett., 1978, 33, 410-412.

52 Y. Dong, G. Zhou, J. Xu, G. Zhao, F. Su, L. Su, G. Zhang, D. Zhang, H. Li and J.-L. Si, Mater. Res. Bull., 2006, 41, 1959-1963.

53 P. A. Tanner, Chem. Soc. Rev., 2013, 42, 5090-5101.

54 K. Suzuki, F. Tang, Y. Kikukawa, K. Yamaguchi and N. Mizuno, Angew. Chem., Int. Ed., 2014, 53, 5356-5360.

55 S. Dey, R. A. Ricciardo, H. L. Cuthbert and P. M. Woodward, Inorg. Chem., 2014, 53, 4394-4399.

56 X.-D. Wen, R. L. Martin, T. M. Henderson and G. E. Scuseria, Chem. Rev., 2013, 113, 1063-1096.

57 O. Gunnarsson and B. I. Lundqvist, Phys. Rev. B: Solid State, 1976, 13, 4274-4298.

58 P. Hohenberg and W. Kohn, Phys. Rev., 1964, 136, B864B871.

59 W. Kohn and L. J. Sham, Phys. Rev., 1965, 140, A1133-A1138.

60 G. Kotliar, S. Y. Savrasov, K. Haule, V. S. Oudovenko, O. Parcollet and C. A. Marianetti, Rev. Mod. Phys., 2006, 78, 865-951.

61 A. Georges, G. Kotliar, W. Krauth and M. J. Rozenberg, Rev. Mod. Phys., 1996, 68, 13-125.

62 V. Anisimov and Y. Izyumov, in Electronic Structure of Strongly Correlated Materials, Springer-Verlag Berlin, Heidelberg, 1st edn, 2010, vol. 3, pp. 47-120.

63 M. C. Gutzwiller, Phys. Rev., 1965, 137, A1726-A1735.

64 X.-Y. Deng, L. Wang, X. Dai and Z. Fang, Phys. Rev. B: Condens. Matter Mater. Phys., 2009, 79, 075114.

65 K.-M. Ho, J. Schmalian and C.-Z. Wang, Phys. Rev. B: Condens. Matter Mater. Phys., 2008, 77, 073101.

66 N. Lanatà, Y. Yao, C.-Z. Wang, K.-M. Ho and G. Kotliar, Phys. Rev. X, 2015, 5, 011008.

67 N. Lanatà, Y. Yao, X. Deng, V. Dobrosavljević and G. Kotliar, Phys. Rev. Lett., 2017, 118, 126401.

68 P. R. C. Kent and G. Kotliar, Science, 2018, 361, 348-354.

69 K. Haule, J. Phys. Soc. Jpn., 2018, 87, 041005.

70 N. Lanatà, T. H. Lee, Y. X. Yao, V. Stevanović and V. Dobrosavljević, npj Comput. Mater., 2019, 5, 30.

71 K. Schwarz and P. Blaha, Comput. Mater. Sci., 2003, 28, 259273. 
72 K. Haule, C.-H. Yee and K. Kim, Phys. Rev. B: Condens. Matter Mater. Phys., 2010, 81, 195107.

73 V. I. Anisimov, F. Aryasetiawan and A. I. Lichtenstein, J. Phys.: Condens. Matter, 1997, 9, 767-808.

74 K. Haule, Phys. Rev. B: Condens. Matter Mater. Phys., 2007, 75, 155113.

75 A. Damascelli, Phys. Scr., 2004, T109, 61-74.

76 H. B. Gray and C. J. Ballhausen, J. Am. Chem. Soc., 1963, 85, 260-265.
77 J. Diwu, A.-G. D. Nelson, S. Wang, C. F. Campana and T. E. Albrecht-Schmitt, Inorg. Chem., 2010, 49, 3337-3342.

78 P. G. Laubereau and J. H. Burns, Inorg. Chem., 1970, 5, 10911095.

79 S. K. Cary, S. S. Galley, M. L. Marsh, D. L. Hobart, R. E. Baumbach, J. N. Cross, J. T. Stritzinger, M. J. Polinski, L. Maron and T. E. Albrecht-Schmitt, Nat. Chem., 2017, 9, 856-861. 